\title{
ESTAMPAS DE LA INDEPENDENCIA EN LAS TRADICIONES PERUANAS DE RICARDO PALMA
}

\author{
Giuseppe BeLlini \\ Universidad de Milán
}

\begin{abstract}
Resumen: Los relatos de las Tradiciones peruanas que Ricardo Palma dedica a la Independencia están dominados principalmente por las figuras de los dos estrategas supremos de la lucha armada, Bolívar y San Martín. Abundan también las alusiones a otros jefes militares de relieve, así como a religiosos que participaron a favor o en contra del proceso independentista, y a todo un variado repertorio de curiosidades de distinta índole que ahondan en la historia y la psicología del momento. A través de sus evocaciones y narraciones, con ironía y humor, Palma hace partícipe al lector del clima de un período central en la trayectoria del Perú.
\end{abstract}

Palabras clave: Independencia, Ricardo Palma, Tradiciones peruanas, Bolívar, San Martín.

Abstract: Among the stories of Ricardo Palma's Tradiciones peruanas related to Independence, there is a prominent group of writings referred to Bolívar and San Martín, supreme strategists of the armed warfare. There are also plenty of allusions to other military leaders of relief, as well as to members of religious orders who took part in favor of or against the independence process, and to a varied collection of curiosities of different nature that go into the history and the psychology of that context. By means of his evocations and narrations, with irony and humor, Palma gives the readers a report of the atmosphere of a central period in the history of Peru.

Keywords: Independence, Ricardo Palma, Tradiciones peruanas, Bolívar, San Martín.

\section{La historia y el "torneo" de Ayacucho}

Bien sabido es que, de todo el continente americano del sur, el Perú fue uno de los últimos baluartes del dominio español en América. Se necesitó la intervención de las tropas de San Martín y sobre todo de Simón Bolívar para que se afirmara definitivamente la independencia del país y decisivas fueron las batallas de Junín y de Ayacucho. 
Antes de la realización del plan independentista se habían verificado, sin embargo, en el país, no pocas tentativas de liberación del yugo español. En 1804, en tiempos del virrey marqués de Avilés, fue descubierta en el Cuzco una conjuración que miraba a constituir un imperio peruano bajo la vieja dinastía incaica, y en tiempos del virrey Abascal, hubo varias rebeliones: en 1811 en Tacna, en 1812 en Huánuco, de nuevo en Tacna en 1813, y en el Cuzco en 1814, la más peligrosa para España, puesto que se extendió a todo el sur del virreinato, con contactos de sus caudillos con los independentistas de Argentina.

Las expediciones en 1819 y 1820 de Cochrane desde Chile a la costa peruana encontraron, por consiguiente, terreno favorable, así como los planes de San Martín para la liberación de todo el Perú. El general argentino con sus 4.000 hombres, llevados por la escuadra de Cochrane, desembarcó a principios de septiembre de 1820 en Paracas, al sur de Lima. El virrey, don Joaquín de la Pezuela, intentó inútilmente negociar, pero la adhesión de algunos generales a los planes de la Independencia y el entusiasmo de los ciudadanos, hizo que el virrey quedara aislado en Lima.

Los acontecimientos fueron varios y contradictorios y sería largo enumerarlos. Bajo el nuevo virrey, teniente general José de La Serna, hubo nuevas tentativas de arreglo con San Martín, que proponía la constitución de una monarquía independiente, bajo un infante español, pero hubo un rechazo general, sea de parte española que de los independentistas. Ante los progresos de los patriotas, el virrey se retiró de la capital para reorganizar el ejército realista en la sierra, y San Martín, a comienzos de julio de 1821, entró en Lima sin combatir; el 28 del citado mes proclamó la Independencia y asumió el mando político con el título de Protector del Perú.

Los independentistas dominaban gran parte del país, la menos poblada. De relieve fueron el pasaje a los patriotas del general José de la Mar, que presidiaba el puerto del Callao, y del general Domingo Tristán, pero no siempre hubo triunfos en las batallas. Por otra parte San Martín iba perdiendo prestigio, debido a sus ideas monárquicas. Convocó entonces un Congreso y decidió entrevistarse con Bolívar en Guayaquil. Lo que trataron los dos personajes ha quedado secreto, pero el resultado fue el regreso a Lima del Protector, quien renunció a su cargo ante el Congreso y en septiembre de 1822 se alejó para siempre del Perú.

La junta de gobierno presidida por el general de la Mar, tras varios desastres militares, fue depuesta por una rebelión de los patriotas, después de una terrible derrota que el general español Jerónimo de Valdés les infligió a las tropas independentistas. Se eligió entonces como Presidente al coronel José de la RivaAgüero, nombrado Gran Mariscal, quien pronto entró en conflicto con el Congreso, el cual nombró a otro presidente, quedando así el poder divivido entre dos mandatarios. 
Nuevos desastres militares decidieron en septiembre de 1823 el Congreso a acudir a Bolívar, el cual fue investido en Lima de la dictadura militar. Decisivas para la independencia del Perú fueron dos grandes batallas: la del 6 de agosto de 1824 en Junín y la sucesiva del 9 de noviembre en Ayacucho, en la que quedó herido y prisionero el mismo virrey de La Serna. Sucre y Bolívar fueron los vencedores, con sus extraordinarios jefes militares y soldados.

El Libertador renunció inmediatamente ante el Congreso a la dictadura militar, que sin embargo le fue confirmada (cf. 1). Época grande para Bolívar, a la que pronto seguiría otra de desconfianza, sospecha y persecución. Queda imborrable la figura del gran jefe venido a menos, cuando se dirige, indeciso, seguido de pocos soldados fieles, hacia un destierro que nunca realizará, como lo presenta $\mathrm{Ga}$ briel García Márquez en su novela El general en su laberinto. Llegado enfermo al fin temprano de sus días, desde la ventana de su cuarto contempla, "ajeno ya a las maravillas del mundo"2, lo que puede ver del cielo:

Entonces cruzó los brazos contra el pecho y empezó a oír las voces radiantes de los esclavos cantando la salve de las seis en los trapiches, y vio por la ventana el diamante de Venus en el cielo que se iba para siempre, las nieves eternas, la enredadera nueva cuyas campánulas amarillas no vería florecer el sábado siguiente en la casa cerrada por el duelo, los últimos fulgores de la vida que nunca más, por los siglos de los siglos, volvería a repetirse ${ }^{3}$.

El vencedor de tantas batallas reducido a hombre común frente a la muerte, última obra maestra la batalla de Ayacucho, que en una de sus Tradiciones, "Pan, queso y raspadura", Ricardo Palma celebra, en su inicio, cual "caballeresco torneo"4, y en la que en realidad murieron tantros hombres.

En efecto, estando los dos ejércitos, realista y patriota, frente a frente, antes de que la batalla tuviera comienzo dos generales, que el narrador define "bizarros" 5 se ponen de acuerdo para que sea posible un último encuentro, en zona neutral, entre amigos y parientes que combatían en los opuestos bandos.

Son las ocho de la mañana del 9 de diciembre: treinta y siete peruanos "entre jefes y oficiales", y veintiséis colombianos, "desciñéndose la espada, pasaron la línea neutral, donde, igualmente sin armas, los esperaban ochenta y dos españoles" 6 . Una media hora de conversación y abrazos afectuosos y luego todos regresaron a sus respectivos campamentos, donde, para los españoles estaba preparado el almuerzo, mientras los patriotas debían contentarse con "pan, queso

1 Datos en L. Ulloa, Manual de Historia de la América española, Barcelona, Seix Barral, 1941.

2 G. García Márquez, El general en su laberinto, Bogotá, La Oveja Negra, 1989, 254.

3 Ibid., 266-267.

4 R. Palma, Tradiciones peruanas completas, ed. y prólogo de E. Palma, Madrid, Aguilar, 1961, 995.

5 Ibid., 996.

6 Ibid. 
y raspadura", fórmula que luego fue el santo y seña del ejército patriota en la batalla.

Pobres y desarrapados los independentistas: si los realistas antes de entrar en combate "se vistieron de gran parada", los patriotas "no podían imitarlos, por no tener más ropa que la que llevaban puesta" 7 . Contraste eficaz: no era el acicalado vestir lo importante, sino el arrojo de quienes luchaban por un gran ideal.

Al momento de empezar la batalla se verificó otro trato de fineza. A las diez volvió a presentarse el general Monet diciéndole al general Córdova "vengo a participarle que vamos a principiar la batalla", recibiendo por respuesta: "-Cuando ustedes gusten, general. Esperaremos para contestar a que ustedes rompan los fuegos", y luego "Ambos generales se estrecharon la mano y volvieron grupas"8.

Entre serio y divertido comenta Palma:

A los americanos nos tocaba hacer los honores de la casa, no quemando los primeros cartuchos mientras los españoles no nos diesen el ejemplo.

En Ayacucho se repitió aquello de: $A$ vous, messieurs les anglais, que nous sommes chez nous 9 .

Leyendo estas páginas de la tradición de Ricardo Palma el lector tiene ciertamente la impresión de un mundo fuera del mundo. La batalla fue, en realidad, extraordinariamente sangrienta, como no podía ser menos, a pesar de las amabilidades de sus jefes antes de su inicio:

Setenta minutos de batalla, casi toda cuerpo a cuerpo, empleando los patriotas el sable y la bayoneta más que el fusil, pues desde Corpahuaico, donde perdieron el parque, se hallaban escasos de pólvora (cincuenta y dos cartuchos por plaza), bastaron para consumar la Independencia de América ${ }^{10}$.

Crueldad de la guerra que ha puesto bien de relieve el mismo Andrés Bello en su Alocución a la poesía ${ }^{11}$, como por otra parte, en sentido triunfal, Joaquín de Olmedo en el Canto a la victoria de Junin:

vimos que al desplegarse

del Perú y de Colombia las banderas, se turban las legiones altaneras, huye el fiero español despavorido, o pide paz rendido.

7 Ibid.

8 Ibid.

9 Ibid.

10 Ibid., 998.

11 A. Bello, "Alocución a la poesiá, en Antologia, ed. G. Bellini, Madrid, Castalia, 2009, donde se reconstruye la identidad de los muchos militares citados. 
Venció Bolívar, el Perú fue libre, y en triunfal pompa Libertad sagrada en el templo del Sol fue colocada. ${ }^{12}$

\section{Protector y Libertador}

En las Tradiciones peruanas referentes a la Independencia las figuras dominantes son las de los dos estrategas supremos de la lucha armada, aunque la persona de San Martín, como ocurre por otra parte en la historia, queda en un segundo plano frente a la de Bolívar. Esto se explica muy bien debido al papel menos importante, a pesar de todo, del general argentino en la realización de la independencia del Perú, y de América en general, sus discutibles, y rechazados, proyectos monárquicos, y al final su abandono de la lucha, cuya prosecución y victoria quedó consignada a los ejércitos grancolombianos de Simón Bolívar.

No faltan, naturalmente, en las Tradiciones, alusiones a jefes militares de relieve, como los generales Sucre y Córdova, y algunos del bando español, juzgados negativa o positivamente, como, en el primer caso, el cruel brigadier don Ramón Rodil, resistente en el castillo del Callao, después de abandonar Lima el virrey de La Serna tras la derrota de Ayacucho ${ }^{13}$, y el incompetente general Canterac; en el segundo sobre todo el general Valdés, que Palma define "el más valiente, honrado y entendido de los generales realistas" 14 , y que, tras la derrota, sus hombres tuvieron que llevárse en peso, decidido como estaba a no abandonar el campo de batalla.

Para mayor escarnio de Canterac, el tradicionista reproduce la carta que el derrotado realista de Ayacucho le envía a Bolívar tres días después de firmada la capitulación. Parecería la conclusión del que Palma había definido en sus comienzos un "caballeresco torneo". La carta del general realista representa todo lo contrario: una sumisión vergonzosa. Escribe el derrotado Jefe de Estado Mayor: "Excelentísimo señor Libertador don Simón Bolívar: Como amante de la gloria, aunque vencido, no puedo menos que felicitar a vuecelencia por haber terminado su empresa, en el Perú, con la jornada de Ayacucho. Con este motivo tiene el honor de ofrecerse a sus órdenes y saludarle, en nombre de los generales españoles, su afectísimo y obsecuente servidor que sus manos besa. José de Canterac, a 12 de diciembre de $1824 " 15$.

Volviendo a San Martín, en las Tradiciones aprendemos más sobre él especialmente a través de las alusiones a sus transportes hacia las mujeres. Como hubo una Libertadora, amante de Bolívar, del mismo modo hubo una Protectora, amante del general argentino.

12 J. J. de Olmedo, “Canto a la victoria de Junín”, en Poesías completas, México, Fondo de Cultura Económica, 1947.

13 Cf. R. Palma, "E1 secreto de confesión" en Tradiciones peruanas completas, op. cit., 1028-1030.

14 R. Palma, "Pan, queso y raspadura", ibid., 998.

15 Ibid., 998-999. 
Cuenta Palma que, cuando chico en el colegio, le chocó el apodo de "protector" que sus compañeros le daban negativamente a uno de los internos, que él frecuentaba y que vivía "en casa de su padre, un alemán huraño de carácter", donde nunca vio "sombra de faldas"16. La curiosidad le movió a desentrañar el motivo y a conocer a la madre del alumno ${ }^{17}$, descubriendo que era doña Rosa Campusano, la que había sido la Protectora, o sea la amante de San Martín.

Anteriormente, sin embargo, cuando en 1817 de Guayaquil llegó a Lima, la joven era amante de un "acaudalado español que barbeaba medio siglo, y cuyo goce era rodear a su querida de todos los esplendores del lujo y satisfacer sus caprichos y fantasías"18. Palabras que ya inducen a pensar cómo sería la muchacha de mimada, en su tiempo una belleza singular, de ojos azules, frisando en los cincuenta cuando la conoció Palma, quien imagina cuántos estragos debió de hacer en su juventud en los corazones masculinos, mientras ahora, si conservaba su fina fisonomía, ya no tenía ni sombra del vigor juvenil, puesto que "Se apoyaba en una muleta con pretensión de bastón"19.

Cuando joven, amante del maduro español, los elegantes salones de doña Rosa habían sido punto de encuentro da la juventud dorada, de condes, marqueses, conspiradores en favor de la Independencia, y cuando llegó a Lima San Martín éste tuvo relaciones con la mujer, sin dar escándalo, "de tapadillo", aunque todos lo sabían ${ }^{20}$. Instituida la Orden del Sol, el general nombró a su amante caballeresa, pero cuando él se alejó de la vida pública su estrella se apagó, sustituída por la de las mujeres de Bolívar. La Protectora acabó viviendo en su vejez con una pensión que le concedió el Congreso. Triste final para quien había vivido en un mundo fastuoso ${ }^{21}$.

Más o menos lo que le pasó a María Abascal, amante de varios, del ministro de Estado, Monteagudo, y de otros despues de él; según Palma "una aristocrática cortesana, una horizontal de gran tono", que no se "encanalló" 22 , y a los cuarenta y cinco años se retiró, convirtió sus riquezas en dinero, lo depositó en casa de un comerciante que en Lima, cuando todavía no existían bancos, hacía las veces de ello: después de veinte años, cuando el comerciante declaró bancarrota, tuvo que reducirse a una casa de pobres que le facilitó el arzobispo.

Del general argentino y su actuación en el Perú, como ya dije, Palma habla poco. Solamente hay una tradición en la que refiere con humor una decisión de

16 R. Palma, "Doña Rosa Campusano ("La Protectora"), ibid., 952.

17 Explica Palma que conoció a la madre de su compañero en los altos de la Biblioteca Nacional, entonces dirigida por "el ilustre Vigil", el cual "concedía habitación gratuita a tres o cuatro familias que habían venido a menos”. Cf. ibid., 953.

18 Ibid.

19 Ibid., 952.

20 Ibid., 953.

21 Del marido alemán de la Campusano y de su hijo no tengo más noticias que la mención de don Ricardo Palma.

22 R. Palma, “"María Abascal”, ibid., 957. 
San Martín contra uno de sus enemigos, cierto Matías Zapata, "un energúmeno frailuco" 23 que le negaba al apellido del general el "San", porque como herético, afirmaba, nada tenía que ver con el Santo. La venganza del ofendido fue quitarle al padre la sílaba inicial "Za", obligándole a firmarse siempre con el apellido de "Pata": "Y cuentan que, hasta 1823, según declara Palma, no hubo en Chancay partida de nacimiento, defunción u otro documento parroquial que no llevase por firma fray Matias Pata", hasta que vino Bolívar, "y le devolvió el uso y el abuso de la sílaba eliminada" 24 .

En cuanto al Libertador y a sus empresas habla la Historia. Pero Ricardo Palma le dedica también repetida atención y en sus Tradiciones es una presencia viva, entre realidad y leyenda, como es el carácter de su libro. En una de estas tradiciones el escritor pone de relieve la justicia que el general sabía realizar con dureza militar. Los soldados independentistas vencedores, los oficiales, sobre todo, debían de ejercer un indudable atractivo sobre la población, en particular femenina, y, como suele ocurrir durante todas las estancias prolongadas de gente armada en el mismo pueblo, las relaciones con el gentil sexo eran la finalidad primera de los militares en descanso: serenatas y bailes lo ordinario, a veces penetrando en ámbitos familiares distinguidos, provistos de hermosas muchachas, con intenciones concretas de aventuras.

Es lo que ocurrió en el departamento de Ancachs en junio de 1824, según relata Palma en la tradición titulada "Justicia de Bolívar", donde un capitán, que con otros compañeros se había metido en casa de una rica familia, quedó mortalmente herido con su misma espada por la dueña de la casa, en el momento en que intentaba aprovecharse de su hija. Bolívar intervino duramente, mandando sepultar el cadáver del culpable "sin los honores de ordenanza", romper la hoja de la espada, "que Colombia le diera, para defensa de la libertad y la moral", en presencia de toda la Compañía ${ }^{25}$ y después del entierro del "delincuente", montado a caballo se dirigió a la casa de la señora ofendida y la saludó con estas palabras: "Saludo a la digna matrona con todo el respeto que merece la mujer que, en su misma debilidad, supo hallar fuerzas para salvar su honra y la honra de los suyos" ${ }^{26}$. El resultado, añade el narrador, fue la conversión inmediata de la señora, que era muy goda, a la causa independentista.

Con estos episodios el tradicionalista celebra al gran hombre que fue el $\mathrm{Li}$ bertador. Lo hace también en otras ocasiones numerosas, construyéndole, entre veras, curiosidades, o fantasías, un monumento de gran interés, al que tampoco falta la documentación de sus amores.

Que Bolívar, nimbado por la gloria, fuese agasajado en todos los lugares donde llegaba y que las mujeres fueran entusiastas de él, es más que natural;

23 R. Palma, "El padre Pata", ibid., 949.

24 Ibid.

25 R. Palma, "Justicia de Bolívar", ibid., 1000.

26 Ibid., 1001. 
atraía el héroe, el vencedor, el hombre poderoso, por más que su figura no fuera de la más linda. Cita Palma un retrato realizado por un "concienciudo historiador", que describe a Bolívar como un hombre "delgado y de algo menos que regular estatura", pero "Vestía bien, y su aire era franco y militar. Era muy fuerte y atrevido jinete", y "Aunque sus maneras eran buenas y sin afectación, a primera vista no predisponía mucho en su favor" ${ }^{27}$, pero las mujeres lo idolatraban.

Así es como llegó a ser su amante, de mayo a noviembre de 1824 - Bolívar era naturalmente voluble-, Manolita Modroño, "un fresquísimo y lindo pimpollo de dieciocho primaveras", pasada más tarde a la historia como "la vieja de Bolívar", orgullosa hasta en su edad senil de haber sido la querida del gran hombre ${ }^{28}$. El cual, sin embargo, sabía también resistir al atractivo femenino, si fue capaz de rechazar las tres doncellas que le deparó el gobernador Guzmán, interpretando los tres etc. que seguían al orden de prepararle —además de idóneo hospedaje y mantenimiento para sus soldados y caballos-, una buena cama "etc., etc., etc.", en ocasión de su visita a Caraz, atento a la fama de mujeriego que tenía el Libertador ${ }^{29}$.

No deja Palma de subrayar el cuidado que Bolívar tenía de su persona, para cuyo aseo gastaba sumas cuantiosas en agua de Colonia, y tanto que "en los cuatro años de su permanencia en el Perú, tuvo el Tesoro nacional que pagar ocho mil pesos, iii 8.000 !!!, invertidos en agua de Colonia para uso y consumo de su excelencia el Libertador" ${ }^{30}$. El cual era consciente de lo que valía si se atrevía a meterse al lado de Jesucristo y Don Quijote. Refiere don Ricardo que, llegado al final de su vida, tuvo con su médico, con voz "muy débil”, el siguiente diálogo, que vale la pena reproducir:

- ¿Sabe usted, doctor, lo que me atormenta al sentirme ya próximo a la muerte? - No, mi general.

- La idea de que tal vez haya edificado sobre arena movediza y arado en el mar.

Y un suspiro brotó de lo más íntimo de su alma y volvió a hundirse en su meditación.

Transcurrido gran rato, una sonrisa tristísima se dibujó en su rostro y dijo pausadamente:

— ¿No sospecha usted, doctor, quiénes han sido los tres más insignes majaderos del mundo?

-Ciertamente que no, mi general.

-Acérquese usted, doctor..., se lo diré al oído... Los tres grandísimos majaderos hemos sido Jesucristo, Don Quijote y... yo. ${ }^{31}$

27 R. Palma, "Bolívar y el cronista Calancha", ibid., 1016.

28 R. Palma, "La vieja de Bolívar", ibid., 1009.

29 R. Palma, "Los tres etcéteras del Libertador", ibid., 1013.

30 Ibid., 1012.

31 R. Palma, "La última frase de Bolívar", ibid., 1053-1054. 
No es la patética despedida de Bolívar presentada por García Márquez, pero resume dramáticamente las dudas de un hombre que, a pesar de todo, construyó un mundo nuevo prometedor, como lo celebra Neruda:

Libertador, un mundo de paz nació en tus brazos.

La paz, el pan, el trigo de tu sangre nacieron, de nuestra joven sangre venida de tu sangre saldrán paz, pan y trigo para el mundo que haremos..$^{32}$

\section{Un examen contrastivo: la Protectora y la Libertadora}

De la amante de San Martín, Palma tiene un concepto aparentemente positivo como mujer, pero en la sustancia negativo comparado con el de la amante de Bolívar ${ }^{33}$. En una de sus tradiciones el narrador peruano realiza una semblanza contrastiva con relación a las dos mujeres, que afirma haber tenido "la buena suerte" de conocer y tratar personalmente, de modo que puede "establecer cardinales diferencias" entre las dos, que "física y moralmente eran tipos contrapuestos" 34 .

El narrador insiste particularmente sobre la femininidad de la Campusano, mientras que en la amante de Bolívar, Manuela Sáenz, destaca el carácter fuerte: si en la primera Palma ve a "la mujer con toda la delicadeza de sentimientos y debilidades propias de su sexo" 35 , en doña Manuela, al contrario, ve "una equivocación de la Naturaleza, que en formas esculturalmente femeninas encarnó espíritu y aspiraciones varoniles" 36 .

Nada más contrastante en dos mujeres que, si no hicieron la Historia, participaron de ella a través de sus amantes. Aunque sí, doña Manuela fue parte activa de la Historia, por la ayuda concreta que dio siempre a Bolívar, salvándole en ocasiones hasta la vida y quedándole siempre fiel hasta después de su muerte. Si doña Rosa fue una mujer sensible, adicta a perfumes refinados, a una conducta de vida más que acomodada, doña Manuela tuvo siempre un carácter fuerte, bastante varonil. La comparación que entre las dos mujeres realiza Palma es tajante. Dos tipos femeninos fundamentalmente diversos frente a la vida:

32 P. Neruda, "Un canto para Bolívar", en Canto general, ahora en Obras completas, vol. I, Buenos Aires, Editorial Losada, 1973 (4a ed. ).

33 Doña Manuela estaba casada con el médico inglés Jaime Thorne, antes de ser la amante del Libertador, y nunca quiso reconciliarse con él, un individuo dispuesto a recIbid.rla de nuevo como su mujer, a pesar de todo. Palma lo define negativamente: "se había convertido de hombre serio en niño llorón, y era, por tanto, más digno de babador que de corbata" (Cf. "La carta de La Libertadora", en Tradiciones peruanas completas, op.cit., 1010-1012). La respuesta de la mujer fue tajante en lo negativo.

34 R. Palma, "La Protectora y La Libertadora", en Tradiciones peruanas completas, op.cit., 962.

35 Ibid.

36 Ibid. 
La Protectora amaba el hogar y la vida muelle de la ciudad y la Libertadora se encontraba como en su centro en medio de la turbulencia de los cuarteles y del campamento. La primera nunca paseó sino en calesa. A la otra se la vio en las calles de Quito y en las de Lima cabalgada a manera de hombre en brioso corcel, escoltada por dos lanceros de Colombia y vistiendo dolmán rojo con brandeburgos de oro y pantalón bombacho de cotonia blanca.La Sáenz renunciaba a su sexo, mientras la Campusano se enorgullecía de ser mujer ${ }^{37}$.

Otros detalles más añade el escritor, como la tendencia en la Protectora al lujo, su gusto por los perfumes refinados, la ostentación de "pedrerías finas", mientras que la Libertadora se adornaba con sencillez y, aún habiendo sido educada por las monjas, era "libre pensadora", en tanto que la primera era "devota creyente" 38 . Doña Manuela sabía dominar sus nervios, se conservaba "serena y enérgica en medio de las balas y al frente de lanzas y espadas tintas en sangre o del afilado puñal de los asesinos" ${ }^{9}$; todo lo contrario la Campusano: "Ésta sabía desmayarse o disforzarse, como todos esos seres preciosos y engreídos que estilan vestirse por la cabeza, ante el graznar fatídico del buho o la carrera de asustadizo ratoncillo" 40 . Sus lecturas eran el "galante" Arriaza, el "dulcísimo" Meléndez, y, según parece por la denuncia del Santo Oficio limeño, una vez vuelto al trono Fernando VII, Eloísa y Abelardo, además de "libritos pornográficos", difusísimos en la época en Lima, para tener algo que confesar, comenta el narrador ${ }^{41}$.

Profundiza Palma la distancia intelectual entre la Protectora y la Libertadora:

¡Qué contraste con las aficiones de doña Manuela! Ésta leía a Tácito y a Plutarco; estudiaba la historia de la península en el padre Mariana y la de América en Solís y Garcilaso; era apasionada de Cervantes y para ella no había poeta más allá de Cienfuegos, Quintana y Olmedo. Se sabía de coro el Canto a Junín y parlamentos enteros del Pelayo, y sus ojos, un tanto abotagados ya por el peso de los años, chispeaban de entusiasmo al declamar los versos de sus vates predilectos. En la época en que la conocí, una de sus lecturas favoritas era la hermosa traducción de los Salmos por el peruano Valdés ${ }^{42}$.

No desdeña don Ricardo, como se ve, el atractivo femenino de Rosa Campusano, pero toda su consideración y respeto van a la amante de Bolívar. Esto se ve también en otra tradición dedicada a "Doña Manuela Sáenz "La Libertadora”, donde representa a la mujer cuando, muerto Bolívar, se retiró en el pueblecito de Paita, una poco halagüeña estación naval. Palma era entonces contador a bordo de la corbeta de guerra Loa, y una vez, bajando a tierra, un amigo le llevó

37 Ibid.

38 Ibid.

39 Ibid.

40 Ibid.

41 Ibid., 962-963.

42 Ibid., 963. 
a conocer a la dama. La encontró sentada en el sillón de ruedas, "con la majestad de una reina sobre su trono", una mujer que le pareció de unos sesenta años, y que "Vestía pobremente, pero con aseo, y bien se adivinaba que ese cuerpo había usado en mejores tiempos, gro, raso y terciopelo"43; abundaba en carnes, pero tenía unos ojos negros "animadísimos, en los que parecía reconcentrado el resto de fuego vital que aún le quedara, cara redonda y mano aristocrática"44.

Un retrato que contrasta con la figura varonil representada en la anterior tradición, donde la compara con la Campusano; pero entonces se trataba de una mujer joven, ahora de una anciana, dimitida el aura de gloria de su vida pasada; una señora digna de todo respeto, también por haber tenido el valor de hacerse a un lado después de haber vivido, con no pocos contrastes, dentro de la aureola de la gloria y la sombra de la derrota de su hombre.

Es probable que a esta tradición de Palma se deba la inspiración primera de Neruda para el largo canto dedicado a La insepulta de Paita, incluido en los Cantos ceremoniales. Va navegando el poeta hacia el Perú y llegado a Paita pregunta por la "bella enterrada"; la respuesta es negativa: "No sabían" 45 , como siempre ocurre con la memoria de los humanos. Sin embargo, el poeta conserva de doña Manuela una imagen viva, la de su juventud, de su valor y su ardor como amante. Por eso lamenta el olvido caído sobre la que se sepultó "en plena vida" y yace "sin sepultura", e interroga al misterio:

dime por qué quedaron mudos
los labios que el fuego besó,
por qué las manos que tocaron
el poderío del diamante,
las cuerdas del violín del viento,
la cimitarra de Dios,
se sellaron en la costa oscura,
y aquellos ojos que abrieron
y cerraron todo el fulgor
aquí se quedaron mirando
cómo iba y venía la ola,
cómo iba y venía el olvido
y cómo el tiempo no volvía:
sólo soledad sin salida
y estas rocas de alma terrible
manchadas por los alcatraces.
Ay, compañera, no comprendo! 46

43 R. Palma, “Doña Manuela Sáenz (“La libertadora”), ibid., 1132.

44 Ibid.

45 P. Neruda, "La insepulta de Paita", en Cantos Ceremoniales, ahora en Obras Completas, vol. II, op.cit..

46 Ibid., XVIII. 
Y un epitafio que resume desde adentro la vida de doña Manuela:

Ésta fue la mujer herida:

en la noche de los caminos

tuvo por sueño una victoria,

tuvo por abrazo el dolor.

Tuvo por amante una espada. ${ }^{47}$

Con Ricardo Palma el poeta chileno comparte el respeto hacia la mujer que tuvo un papel extraordinario en la historia de la Independencia americana.

\section{Eclesiásticos excomulgadores y frailes de combate}

En general curas y frailes adversaron la Independencia americana y sus partidarios, pintándolos como expresiones del Anticristo, y amenanzando excomuniones. Enemigo acérrimo de la causa libertadora fue el obispo de Mainas, el franciscano fray Hipólito Sánchez Rangel, el cual "era godo de tuerca y tornillo" 48 y excomulgaba a los que tenían simpatías por los insurgentes. Palma reproduce del citado obispo una pastoral durísima:

"A cualquiera de nuestros súbditos que jurase la escandalosa independencia lo declaramos excomulgado vitando, y mandamos que sea puesto en la tablilla, y si fuere eclesiástico lo declaramos suspenso, lo ponemos en entredicho local y personal, y mandamos consumir las especies sacramentales y cerrar la iglesia, hasta que se retractase y jure de nuevo ser fiel al rey. Y si algunos de nuestros hijos oyere misa de sacerdotes insurgentes o recibiere sacramentos, lo declaramos también excomulgado vitando, por cismático o cooperador del cisma político y religioso" 49 .

Sin embargo, visto el desarrollo de las cosas, a fines de 1821 fray Hipólito decidió largarse y embarcó en Huallaga rumbo al Pará, cargando con un verdadero tesoro en monedas de oro. El barco hizo naufragio y todo se perdió. Con humor don Ricardo anota: " $¡$ Cuán cierto es aquello de que nadie sabe para quien trabaja!" 50 , y en efecto disfrutaron del tesoro ido a pique los pescadores de Chasuta, que un día dieron con los veinte mil godos del obispo.

De fray Matías Zapata y su aventura ya he dicho, pero no hubo solamente frailes realista sino varios interventistas, empujados a combatir contra los realistas por motivos varios. En la tradición titulada "El coronel fray Bruno", Palma ofrece una serie de nombres de religiosos que combatieron con los independentistas, algunos acabando su vida como descreídos y pendencieros, como el

47 Ibid., XI.

48 R. Palma, "Los veintemil godos del Obispo", ibid., 947.

49 Ibid.

50 Ibid., 948. 
argentino fray Félix Aldao, de la orden de la Merced, capellán de un regimiento de San Martín, que "sable en mano, se metía siempre en lo más reñido del combate" ${ }^{51}, \mathrm{y}$ era también un jugador empedernido; en el Perú ganó una vez una gran suma, lo que le decidió a largarse llevándose, "con disfraz de paje, una linda muchacha, a quien sedujo" 52 . En la época de Rosas, en la Argentina, ascendió a general, pero condujo siempre una vida violenta y pecaminosa:

El fraile Aldao se entregó furiosamente a la embriaguez y la lascivia, no dejó crimen por cometer como seide del tirano argentino, y murió (ejerciendo el cargo de gobernador o autócrata de Mendoza) devorado por un cáncer en la cara, blasfemando como un poseído ${ }^{53}$.

Por contraste, la actuación y la vida del coronel fray Bruno Terreros, a quien dedica Palma la tradición mencionada, fue la de un hombre honrado, que se lanzó a la guerra contra los realistas debido a la violencia y a los robos sacrílegos que la soldadera en su momento de crisis iba cometiendo en los pueblos y las iglesias: "Para él la guerra tenía el carácter de guerra religiosa, y sabía inflamar el ánimo de sus montoneros arengándolos con el Evangelio en una mano y el trabuco en la otra", y ellos lo seguían convencidos de combatir, más que por su patria, por Dios y conquistarse así la "salvación eterna" 54 .

Difidicultades encontró fray Bruno cuando, terminada la lucha armada con la victoria de los independentistas, quiso reintegrarse a su orden religioso, y tanto que tuvo que intervenir el mismo Libertador con dos cartas de su secretario al arzopispo para que lo aceptaran entre los frailes y le dieran un curato: él eligió el de Mito, que era el pueblo de su nacimiento.

En la lucha independentista tomaron parte también otros religiosos combativos. Menciona Palma al coronel franciscano fray Luis Beltrán, "que fue quien fundió los cañones que trajo San Martín a Chacabuco" e, "injustamente desairado" un día, en Trujillo, por el Libertador, intentó asfixiarse; lo salvaron pero se volvió loco, más tarde sanó de la locura, volvió a su orden en Buenos Aires y poco tiempo después murión 55 .

De una u otra manera la participación de religiosos en la lucha por la Independencia fue un fenómeno interesante. Lo mismo había ocurrido en España cuando la lucha contra los franceses, en tiempo de la invasión napoleónica.

\section{Curiosidades}

Las Tradiciones peruanas ofrecen, además de lo expuesto en los párrafos anteriores, varias curiosidades ligadas al período de la lucha por la Independencia,

51 R. Palma, "El coronel fray Bruno", ibid., 966.

52 Ibid.

53 Ibid.

54 Ibid.

55 Ibid., 967. 
que ahondan en la historia y la psicología del momento. Por ejemplo cómo cierta aristocracia peruana entendía el servicio militar. Lo vemos en "Un general de antaño", tradición en la que Palma presenta con sugestiva ironía a Juan José Larrea, "un jovencito de la primera aristocracia del Cuzco", nombrado alférez por el virrey La Serna, "que en clase inferior no podía principiar quien era deudo de condes, marqueses y caballeros de Santiago, Alcántara y Calatrava" ${ }^{56}$, en el momento en que se apresta a incorporarse al regimiento realista que los suyos le habían escogido, el del general español Jerónimo Valdés.

Subraya el escritor que para el joven y su familia "la milicia tenía ante todo el atractivo del relumbrón en el uniforme. Imaginábanse que un joven de sangre azul, rico y buen mozo, tenía con sólo estas dotes más de lo preciso para llegar en un par de añitos a general, por lo menos, o a virrey del Perú ${ }^{57}$. Por eso el joven se apresta a tomar servicio en el ejército después de una semana de preparativos, provisto de sesenta onzas de oro para sus "gastos menudos, y un equipaje de príncipe en cuatro mulas cargadas con baúles de ropa, vajilla de plata cendrada, cama-almofrej y provisiones de boca, amén de dos criados para su servicio"58.

A lo largo del trayecto pasa la noche en una posada, donde, como amante de la compañía, invita a cenar con él a un viajero que ya dormía roncando, despertándolo con el pie. Sus criados en tanto lo estaban disponiendo todo con esmero:

Mientras uno de los criados condimentaba en la cocina un sabroso chupe de huevos y papas amarillas, el otro colocaba en una esquina del cuarto la camaalmofrej, con sábanas de holanda y colcha bordada de damasco filipino. En seguida armó una mesita de campaña que en el equipaje venía, tendió sobre ella finísimo mantel, puso cubiertos y copas de plata, abrió cajas de conservas, alineó botellas de excelentes vinos, y cuando el cocinero se presentó con su contingente avisaron al amito que la cena lo esperaba ${ }^{59}$.

El tono satírico de toda la presentación del joven alférez revela claramente las antipatías de Palma por el bando realista. Que un señorito se encaminara a tomar su puesto en la milicia con todo el rumboso equipaje descrito parece imposible, pero el tipo entraba a formar parte del bando enemigo y ya se ha visto como también antes de la batalla de Ayacucho el escritor subraya cómo los oficiales españoles se vistieron para la batalla con sus mejores uniformes, contraste eficaz con la pobreza de vestuario de los independentistas.

De todos modos, la sustancia de la tradición se cifra en la dura lección que el huésped invitado por el joven patricio a su mesa le da la mañana siguiente: el

56 R. Palma, "Un general de antaño", ibid., 985.

57 Ibid.

58 Ibid.

59 Ibid., 986. 
consejo es de que devuelva a su casa todo lo que ha traído, y a la reacción picada del señorito se le revela ser el general Valdés.

Divertida es la tradición en la que Palma explica el origen y significado de la frase "la maldición de Milve", que las mujeres empleaban para las muchachas que quedaban solteras. Milve era un gringo, general independentista, el último en abandonar Arequipa ante la avanzada de los españoles. La ciudad era muy goda y cuando el militar pasó, último en la retirada, bajo el balcón de "tres damas de lo más encopetado" de la ciudad, tres hermanas, subraya Palma, "poco favorecidas por la Naturaleza con dotes de hermosura, y sin más gracia que la del bautismo; en suma tres muchachas feas", ellas virtieron, riendo a carcajadas, "ácido úrico" sobre el militar. El cual se quitó el sombrero para sacudirlo y "con la flema que caracteriza a los ingleses" pronunció, dirigiéndose a las tres, esta frase: “Permita Dios que siempre duerman solas!", "maldición que fue de gitano" — asegura don Ricardo-, "porque las tres hermanas murieron, cuando Dios lo dispuso, sin haber probado las dulzuras del himeneo" 60 .

Una tradición interesante que introduce en la vida conventual femenina es la que trata de "Un Tenorio americano", referente al joven general argentino Artigas, que oyendo cantar divinamente a una hermosa monjita en la iglesia de Chuquisaca, no solamente de modo irritual la aplaude a viva voz, sino que estrecha con ella relaciones amorosas, penetrando de noche en el convento. Del grave escándalo lo saca el mariscal Sucre, convenciendo al silencio la indignada abadesa.

Pero, ¿quién era la joven monjita? Una recluída por su rico padre en el convento por haberse negado a casarse con un acaudalado comerciante, un tipo que Palma describe como "hombre vulgar y prosaico, una especie de asno con herrajes de oro", así que se explica cómo "siendo la chica un tanto poética y soñadora" 61 , se opusiera tozudamente al proyecto paterno.

Por otra parte, en el convento de las monjas de Chuquisaca la vida para la joven fue pronto fácil y hasta divertida. La madre superiora y las demás monjas le manifestaban afecto y amplia comprensión, puesto que era mujer linda y cantaba divinamente. Palma presenta eficazmente la situación:

como el ascetismo monacal no estaba encarnado en su espíritu, y como la regla de las mónicas en Chuquisaca no era muy rigurosa, nuestra monjita se economizaba mortificaciones, asimilando, en lo posible, la vida del convento a la del siglo. Vestía hábito de seda, y entre las mangas de su túnica dejábase entrever la camisa de fina batista con encajes. En su celda veíanse todos los refinamientos del lujo mundano, y el oro y la plata se ostentaban en cincelados pebeteros y artística vajilla. Dotada de una voz celestial, acompañábase en el clave, la vihuela o el arpa, que era hábil música, cantando con suma gracia cancioncitas profanas en la tertulia que, de vez en cuando, la permitía dar la superiora,

60 Todas las citas en R. Palma, "La maldición de Miller", ibid., 992.

61 R. Palma, “Un Tenorio americano”, ibid., 1044. 
cautivada por el talento, la travesura y la belleza de Isabel. Esas tertulias eran verdaderas fiestas, en las que no escaseaban los manjares y las más exquisitas mistelas y refrescos ${ }^{62}$.

¡Como si don Ricardo lo hubiera visto todo con sus ojos! Ninguna novedad, por otra parte, valga el convento en el que pasó su vida Sor Juana en México. Naturalmente asoman en esta descripción la picardía del tradicionalista y cierto anticlericalismo moderado, propio de la época y de un hombre desencantado.

\section{Despedida}

No seguiré con otros detalles, presentes numerosos en las Tradiciones inherentes al período de la guerra de Independencia. Todo lo apuntado es cosecha de don Ricardo Palma; yo no hice otra cosa que actualizar páginas que a estas alturas están, probablemente, sumidas en un olvido ciertamente injusto.

Nada tan interesante y vivo, a pesar del transcurso del tiempo, como las evocaciones y narraciones del gran escritor que, con sorna, ironía y humor, participa al lector el clima de un período central de la trayectoria histórica del Perú.

\section{BIBLIOGRAFÍA}

Bello, A., "Alocución a la poesía", en Antología, ed. G. Bellini, Madrid, Castalia, 2009. García Márquez, G., El general en su laberinto, Bogotá, La Oveja Negra, 1989.

Neruda, P., "Un canto para Bolívar", en Canto general, en Obras completas, vol. I., Buenos Aires, Editorial Losada, 1973.

—, "La insepulta de Paita", en Cantos Ceremoniales, en Obras Completas, vol. II, Buenos Aires, Editorial Losada, 1973.

Olmedo, J.J. de, "Canto a la victoria de Junín”, en Poesias completas, México, FCE, 1947. Palma, R., Tradiciones peruanas completas, ed. y prólogo de E. Palma, Madrid, Aguilar, 1961.

ULLoA, L., Manual de Historia de la América española, Barcelona, Seix Barral, 1941. 